\title{
Industry strategies for the promotion of E-mobility under alternative policy and economic scenarios
}

\author{
Gillian Harrison ${ }^{1,2^{*}}$ (D), Jonatan J. Gómez Vilchez ${ }^{1}$ (1) and Christian Thiel ${ }^{1}$
}

\begin{abstract}
Purpose: In this study, we consider the European electro-mobility market from an industrial perspective, and focus on effects of market conditions and manufacturer strategies, with the objective to gain insight on what could inhibit the successful market penetration of electric powertrain vehicles.

Methods: We use the EC-JRC Powertrain Technology Transition Market Agent Model (PTTMAM), a system dynamics model based around the interactions of conceptual market agent groups in the EU. We assess strategies employed by automobile manufacturers towards the development and market penetration of electric vehicles.

Results: Impacts on electric powertrain sales shares (up to 2050) related to industrial strategies, represented by learning effect, marketing effort and R\&D funding, are presented under different scenarios related to policy, regulation and market conditions.

Conclusion: It is concluded from the results presented here that competition between electrical powertrain options may be more inhibitive than competition against conventional counterparts, with both monetary and non-monetary industry support for immature powertrains key to their long-term success when supportive policies are designed to be technology neutral.
\end{abstract}

Keywords: Electro-mobility, Automobile industry, System dynamics modelling, EU

\section{Introduction}

The 2016 European Strategy for Low Emission Mobility [1] supports the transition towards low and zero emission vehicles, building on the aim of the 2011 Transport White Paper [2] to reduce road transport emissions and the use of conventional vehicles in cities. It is widely accepted that electric vehicles (EVs) will form a major part of achieving the targets set in these documents. Although EVs are not completely without environmental impact, due to upstream greenhouse gas (GHG) emissions and manufacturing processes, studies have suggested that EVs can have substantially lower overall GHG emissions

\footnotetext{
* Correspondence: drgillianharrison@gmail.com

The work was carried out at Joint Research Centre and Gillian Harrison has since moved to University of Leeds.

${ }^{1}$ European Commission, Joint Research Centre (JRC), Directorate Energy, Transport and Climate, Sustainable Transport Unit, Via E. Fermi 2749, 1-21027 Ispra, VA, Italy

${ }^{2}$ Institute for Transport Studies, University of Leeds, 34-40 University Road, Leeds LS2 9JT, UK
}

than conventionally fuelled Internal Combustion Engine Vehicles (ICEVs) [3, 4]. On that basis, this paper explores the potential of e-mobility in the European Union (EU).

EVs are already gaining a credible market position in Europe [5]. However, many factors will affect their longterm embedment into mobility patterns and preferences. Given the motivation for the accelerated introduction of EVs to reduce both global GHG emissions and local air pollution, governments can encourage take up through incentivising the purchase of the vehicles to potential EV owners [6], investing in the development of technology and infrastructure, or indirectly by regulating emissions with associated penalties for manufacturers not achieving the desired standards $[7,8]$. In this study, we consider the industrial perspective, and focus on effects of market conditions and manufacturer strategies, with the objective to gain insight on what could inhibit the successful market penetration of Plug-in Hybrid EV (PHEV), Battery EV (BEV) and Fuel Cell EV (FCV) (see Table 1 for definitions). 
Table 1 Key acronyms for powertrains used in this paper

\begin{tabular}{|c|c|c|}
\hline Acronym & Term & Description \\
\hline$\overline{E V}$ & Electric Vehicle & $\begin{array}{l}\text { Any vehicle powered by an electric } \\
\text { powertrain. }\end{array}$ \\
\hline PiEV & Plug-in Electric Vehicle & $\begin{array}{l}\text { A vehicle with an electric powertrain } \\
\text { which requires (at least in part) } \\
\text { charging from an external source. }\end{array}$ \\
\hline BEV & Battery Electric Vehicle & $\begin{array}{l}\text { A vehicle with an electric powertrain } \\
\text { fully powered by an internal battery } \\
\text { charged from an external source. }\end{array}$ \\
\hline PHEV & $\begin{array}{l}\text { Plug-in Hybrid Electric } \\
\text { Vehicle }\end{array}$ & $\begin{array}{l}\text { A vehicle with an electric powertrain } \\
\text { which can be powered by either an } \\
\text { internal battery charged from an } \\
\text { external source or from an internal } \\
\text { conventionally fuelled combustion } \\
\text { engine. }\end{array}$ \\
\hline FCV & Fuel Cell Electric Vehicle & $\begin{array}{l}\text { A vehicle with an electric powertrain } \\
\text { powered by a hydrogen fuel cell. }\end{array}$ \\
\hline
\end{tabular}

\section{Previous research}

There is already a significant body of work studying the various policies related to EVs - recent examples include [9-12]. However, further support to the transition may be outside the control of authorities, such as market conditions and the strategies adopted by the industry.

Modelling the transition of automobile technologies has long been a subject of research, from studies of car ownership in the early twentieth century $[13,14]$ through the increased interest in vehicle choice from the late 1970s [15-17] and more recently the impact of zero tailpipe emission vehicles as part of emission reduction strategies $[18,19]$. However, the number of studies considering the industrial perspective is currently low in the English language (see [20-22]). The German automotive industry has been examined using system dynamics in various theses published in German [23-25], as has the Japanese market [26].

Complex real-world systems can be studied with system dynamics (SD) modelling, which is based on theory of nonlinear dynamics and feedback control [27]. Accumulations (stocks) and movement (rates) within a system of interrelating variables are represented by simultaneous equations that are repeated over a period of time, allowing evolution of the outputs. Developed by Jay W. Forrester in the 1950s and applied extensively in business management, it is being increasingly applied to other disciplines. System dynamics modelling has long been applied to transport [28] and in particular the uptake of alternative fuel vehicles [29]. Most previous models have focused on specific technologies, market agents or regions, whereas the Powertrain Technology Transition Market Agent Model (PTTMAM) is one of the most comprehensive models of its type.

\section{Method}

The objective of this study is to investigate the role of manufacturer strategies in relation to market and policy conditions. To accomplish this, we employ a system dynamics model of transitions in the light duty road transport technology market in the EU, the PTTMAM. Built around four conceptual groups of market agents (user, manufacturer, infrastructure provider, authorities) it is designed to capture the key decision rules, interactions and feedbacks within the system between 1995 and 2050. It covers all current 28 Member States (MS) of the Union (EU28) and 16 separate powertrain types. The model has been described extensively in previous publications [30-32], and a publically available technical report [33]. Unlike these studies, the focus here is on the manufacturer, which for simplicity is nominally represented as one conglomerate within the PTTMAM. Modelling the supply-side as a small set of interacting agents would yield a more realistic representation of the market structure under which vehicle manufacturers operate. However, it would require the linkage with other methods that may be more suitable for this purpose, such as agent-based modelling. Therefore competition is considered not among manufacturers but among powertrain technologies. Initially in the simulation, competition among powertrains is low and conventional technologies dominate. Over time, competition among powertrains is likely to increase, driven by industry strategies as influenced by policy and economic conditions. To improve the competitive position of a powertrain, manufacturers are assumed to have three main instruments at their disposal (see Table 2 and section 5.3). Manufacturers make forecasts of potential future penalties and make adjustments to their strategies in order to avoid penalties (see Technical Report for full detail on this). The main mechanism for this is by increasing Research and Development (R\&D) funding in relevant components in order to accelerate their maturity, but they can also alter their pricing and marketing strategies towards lower emission powertrains (to represent competition). This price is calculated endogenously in the model and includes both fixed and variable costs of the manufacturer for the production of the vehicle components, manufacturer mark up, adjustments for e.g. penalty avoidance, portion of accrued penalties filtering through to users, and vehicle taxes. Vehicle market shares are determined through User purchase decisions made through a choice model based on the perceived

Table 2 Variables tested by thematic area

\begin{tabular}{lll}
\hline Policy and Regulation & Economic Conditions & Manufacturer Strategies \\
\hline - Emission regulations & $\cdot$ GDP ratio & $\cdot$ Learning rate \\
- Purchase subsidies & $\cdot$ Oil price & $\cdot$ Marketing effort \\
- Infrastructure subsidies & & $\cdot$ R\&D share \\
\hline
\end{tabular}


utility of a vehicle, itself formed through vehicle attributes that develop through time (e.g. performance, emissions, convenience, cost).

It was of interest in this study to look at both push and pull effects on EV uptake, coming from policy and regulation, market conditions and manufacturer strategies. In this section we will describe the inputs and scenarios we have applied. To create scenarios that represent the influence of policy, manufacturer and economic market conditions on EV uptake, we have chosen to focus on a number of variables within the PTTMAM. It is assumed that EV uptake will be sensitive to all of these variables, and that increasing them will be beneficial for uptake, whereas decreasing them would inhibit uptake, relative to a baseline scenario. In the results section we explore the impacts of the scenarios on sales market shares of BEV, PHEV and FCV.

\section{Scenario overview}

In total, 58 scenarios were tested in this study (see full list in Appendix), with variables in three thematic areas, shown in Table 2.

Two levels of fleet emission regulatory targets and four levels of purchase subsidies were considered, and each of the economic conditions and manufacturer strategy variables were tested at a Base value and two extremes. Whereas the minimum represents a halving of the baseline values, the maximum entails doubling. As previous studies identified strong interactions between powertrains, certain tests were carried out with FCV excluded to explore the effect of if it never actually enters the market at larger scale, though it is noted that there are already some variants on sale in Europe (e.g. Toyota Mirai and Hyundai ix35). A full list of scenarios is available in the Appendix, and the scenario inputs are described in more detail in the next section.

\section{Scenario inputs}

\subsection{Policy and regulation}

Two levels of EU fleet emission regulations were applied. Base represents the current fleet emission regulation target in place [7], i.e. only a $95 \mathrm{gCO}_{2} / \mathrm{km}$ target from 2021 . A second Mid scenario has tighter targets based on [34]: $85 \mathrm{gCO}_{2} / \mathrm{km}$ in $2025,75 \mathrm{gCO}_{2} / \mathrm{km}$ in 2030 and $25 \mathrm{gCO}_{2} /$ $\mathrm{km}$ in 2050). Within the PTTMAM, manufacturers are represented as one conglomerate market agent. The specific emission target is calculated as per the regulations, based on average vehicle mass and the target as given. Average emissions for new vehicles of each powertrain and size in each MS are calculated endogenously. This is based on the annual powertrain sales shares of new vehicles, calibrated emission inputs at the start of the time frame, and the improvement over time is related to the degree of manufacturer investment in $R \& D$ of components relevant to the emissions efficiency (termed 'environmental attribute' in the PTTMAM). Thus, excess emissions are determined from the difference between this and the specific target emissions, and manufacturers are penalised according to the regulations (which is up to $€ 95$ per $\mathrm{gCO}_{2} / \mathrm{km}$ ).

In the model purchase subsidies are assumed across the whole EU and are represented by a reduction in the cost differential between the alternative powertrain and the relevant conventional ICEV (see Table 3). The base values of this (S1) were determined in previous work as being representative of current subsidy programmes [31], and for our extended scenarios we continue the lowest level of subsidy for increasing durations up to 2025 (S2) and 2050 (S3). These are a data input into the PTTMAM which directly reduces the vehicle nominal price to the user. In addition to the purchase subsidy scenarios, a fourth subsidy scenario was created to explore any additional impact from infrastructure subsidies. This scenario, S4, includes the base purchase subsidies plus 100\% infrastructure subsidies from 2015.

\subsection{Economic conditions}

Gross domestic product (GDP) and oil price were chosen as indicators of crucial economic conditions. Both GDP and oil price influence total sales turnover, therefore these variables are beyond the direct control of the industry but could severely impact technology transitions.

Total demand for vehicles at each time step and for each country is calculated using calibrated parameters, the initial 1995 demand [35], GDP ratio (the current GDP per capita relative to the initial GDP per capita [36, 37]) and household ratio (the current number of households relative to the initial number of households (calculated from population [36, 38] and household size [36])). In addition to the total vehicle demand, GDP ratio can also affect the affordability of a certain powertrain which impacts the willingness to consider [39] and total cost of ownership of a powertrain, that in turn determine the powertrain utility and thus sales share of the total demand. Base GDP ratio is shown in Fig. 1.

Table 3 Subsidy scenarios

\begin{tabular}{llll}
\hline Scenario & Period & $\begin{array}{l}\text { Purchase Subsidy } \\
\text { (Cost differential } \\
\text { from ICEV) }\end{array}$ & $\begin{array}{l}\text { Infrastructure } \\
\text { Subsidy (100\%) }\end{array}$ \\
\hline S1 (Base) & $2011-13$ & $50 \%$ & Not available (N/A) \\
& $2014-15$ & $25 \%$ & N/A \\
S2 & $2011-13$ & $50 \%$ & N/A \\
& $2014-25$ & $25 \%$ & \\
S3 & $2011-13$ & $50 \%$ & $2015-50$ \\
& $2014-50$ & $25 \%$ & \\
S4 & $2011-13$ & $50 \%$ & \\
& $2014-15$ & $25 \%$ &
\end{tabular}




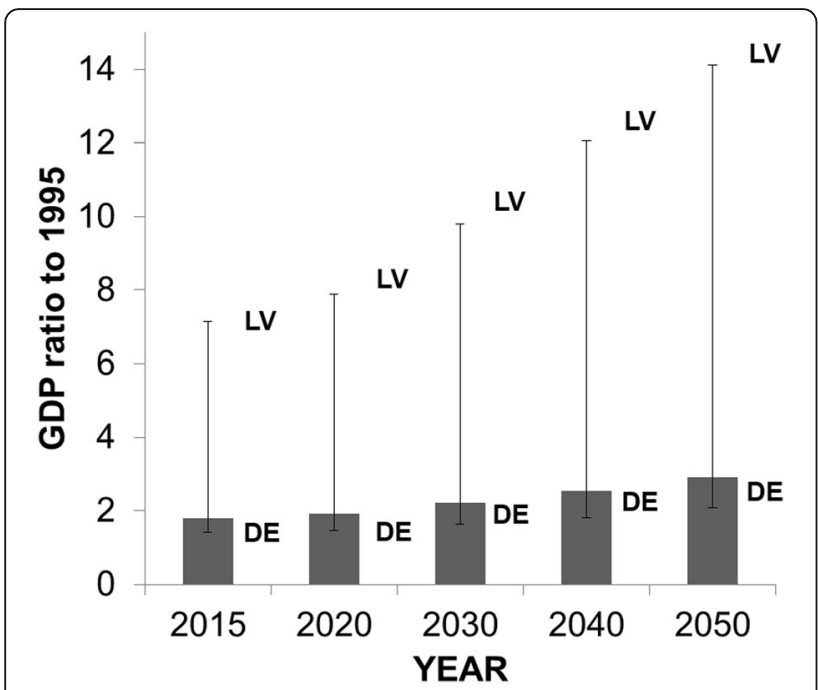

Fig. 1 Base Average EU GDP Ratio (weighted by population and showing deviation between maximum (Latvia- LV) and minimum (Germany - DE)

Oil price influences sales share of powertrains as part of the variable ownership costs. In the PTTMAM, the user choice model of the utilities of the powertrain options is scaled by a financial attractiveness parameter. This is the financial performance relative to the average. Financial performance comprises the total cost of ownership and the fraction of the baseline vehicle cost. This consists of the vehicle purchase price and ownership costs over a 5 year period (the assumed length of first time ownership). The user is assumed to only consider a weighting of $20 \%$ of the total cost of ownership in the purchase decision. Ownership costs include insurance, depreciation, financing, maintenance, taxes and fuel costs. Fuel costs are determined from average annual mileage [40], fuel consumption (reduced from an initial input [41] relative to investment in components calculated endogenously) and the nominal petrol price (seen in Fig. 2, illustrative for Germany) derived from current fuel costs [42], taxes [40] and forecast changes in oil price [36].

\subsection{Manufacturer strategies}

To represent manufacturer strategies, three further variables were chosen, which could reasonably be argued are within the sphere of influence of the manufacturer.

The effect of learning reduces cost of each component (Electric Drive System, Electric Motor, Batteries, Fuel Cell System, H2 storage tank, ICE, and Body) over time in the simulation, based on a base input of $10 \%$ learning rate [31], an initial calibrated component cost (based on [43]) and relative to the cumulative production of that component. As all technologies have the same learning effect less mature technologies will benefit more with a greater cost reduction curve. The cost of the component then contributes to the total vehicle price. As well as cost, the learning effect accelerates the development of the components, which in turn improve the attributes of the vehicle that increase overall vehicle utility to the user. The base effect of learning on cost for each component is shown in Table 4. It is assumed that manufacturers have a degree of control in the strength of learning curve by the amount of resources they dedicate to the component, however in the PTTMAM this is not explicitly included. We have also further explored the impact of learning rates on individual powertrains - for FCV the components $\mathrm{H}_{2}$ storage tank and fuel cell system, and for PiEVs the batteries are halved and doubled.

Marketing effort represents the strength of promotion of a powertrain and feeds into awareness of the user. It directly influences the environmental importance a user gives a powertrain in their purchase decision, and through marketing effect, total social exposure and ultimately the willingness to consider a powertrain in their decision set. It is translated into marketing effect using a base response (i.e. the growth in awareness resulting from the base marketing effort) of $25 \%$ a year. The base

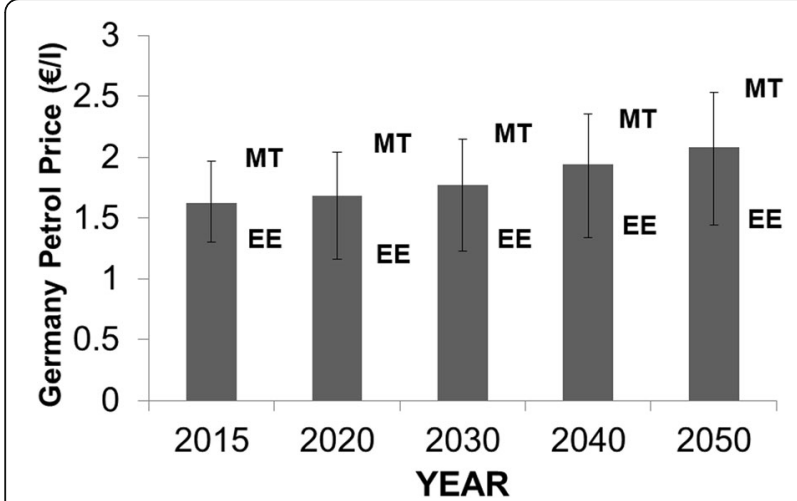

Fig. 2 German petrol price under base conditions $(€ / I)$, showing maximum (Malta - MT) and minimum (Estonia - EE)
Table 4 Effect of learning on cost and cumulative manufacturer spend of individual components under base scenario

\begin{tabular}{llll}
\hline Component & \multicolumn{2}{l}{ Learning Effect on Cost } & Cumulative R\&D \\
\cline { 2 - 3 } & Base (1995) & Minimum (2050) & spend to 2050 (€B) \\
\hline Electric Drive System & 1 & 0.22 & 100 \\
BEV Battery & 1 & 0.28 & 99 \\
HEV Battery & 1 & 0.24 & 98 \\
PHEV Battery & 1 & 0.27 & 99 \\
IC Engine & 0.85 & 0.84 & 1488 \\
Hydrogen Storage & 1 & 0.54 & 90 \\
Tank & & 0.16 & 300 \\
Body Materials & 0.20 & 0.54 & 92 \\
Fuel Cell System & 1 & & \\
\hline
\end{tabular}


marketing effort for each country and powertrain is determined in a base level of forecast sales share of 0.35 that triggers marketing and sensitivity to changes of 1.2. It is then adjusted according to the degree of extra effort required to encourage the adoption of lower-emission powertrains in order to avoid potential emission penalties, as well as in proportion to any subsidies that are available. Thus the manufacturer is assumed to reduce marketing of this powertrain.

The RED share of the funds is the proportion of revenue made available for developing immature powertrain components. An assumption is made in the model that $5.6 \%$ of revenue funds R\&D and $75 \%$ of this is allocated to the improvement of these components. The total investment by 2050 is shown in Table 4, though this is in relation to a capped amount of estimated spend to full maturity. The total amount of R\&D funds are shared between powertrains according to their relative future profits, a measure of the current powertrain maturity and adjusted to reduce potential future emissions and avoid regulatory penalties. The component share of the total powertrain $R \& D$ spend is determined as a function of the remaining potential improvement in the component, the contribution of the component to powertrain attributes and the importance of the attributes to the user.

\section{Results}

\subsection{Impacts on EV sales shares \\ 6.1.1 BEV sales share}

Figure 3 shows the evolution in BEV sales shares between 2015 and 2050 under different scenarios. For BEV, all variables would appear to mainly act in an expected way up to 2030 under both Base and Mid Targets. There is little difference in magnitude or market penetration rates between Base and Mid until shortly before new targets are imposed in 2025. A small exception to this is reduced learning under the Mid target, which has led to marginally higher shares than either the baseline or maximum learning rate scenario by 2030 . This occurs because from around 2025 the minimised learning rate exhibits a more rapid rate of sales growth than other
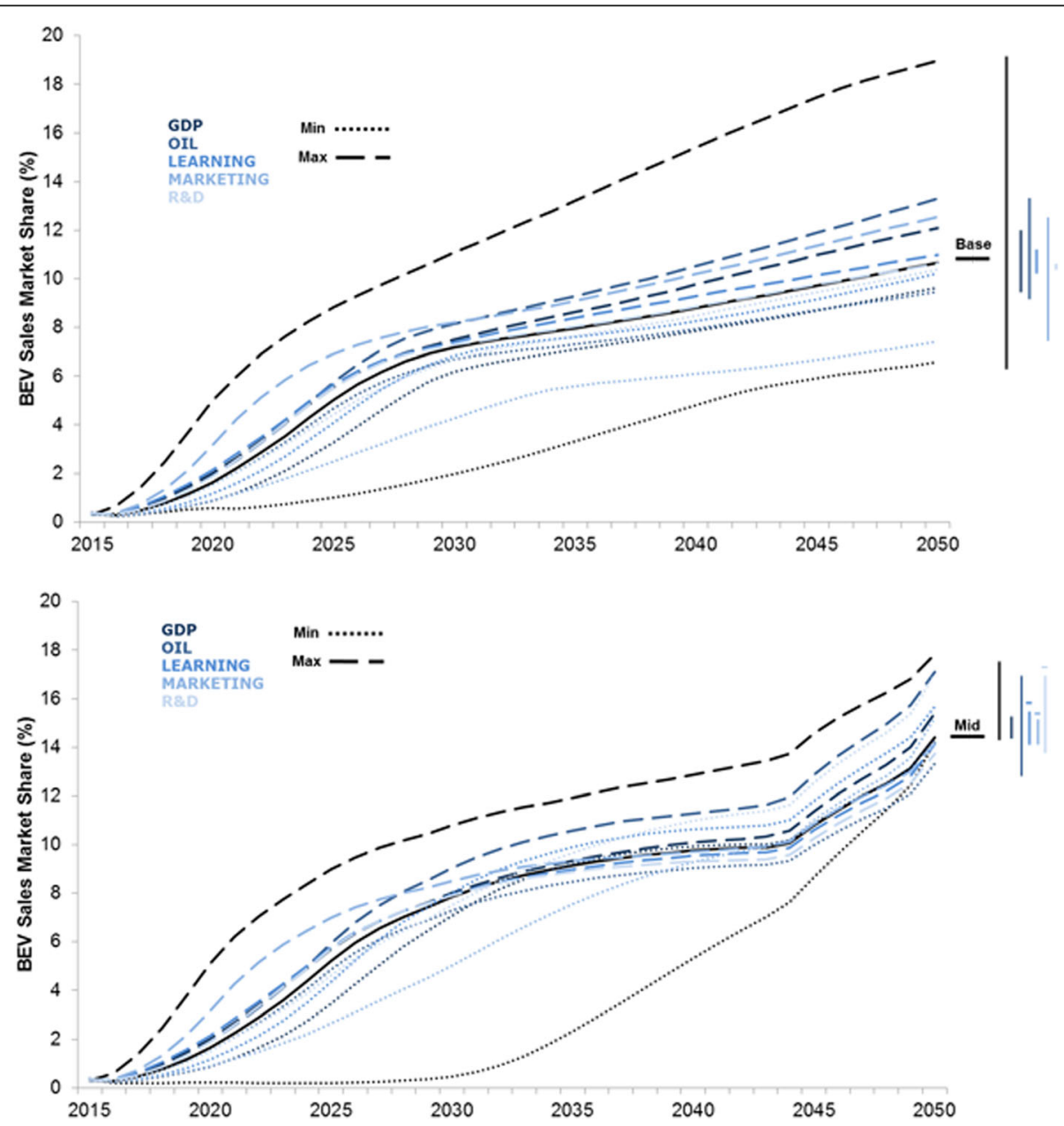

Fig. 3 EU 28 BEV sales share to 2050 under Base (top) and Mid (bottom) fleet emission targets, showing range between Min and Max scenarios 
scenarios. By this time the BEV has become relatively mature, so learning rates are more beneficial for the less mature FCV - making it more competitive - thus a lower learning rate is relatively beneficial for the BEV. Another anomaly is a higher sales growth rate (compared to baseline) when marketing is stronger at the start of the simulation, and a lower growth towards the end. This indicates that strong marketing when the BEV is first introduced is an important variable, but this boost is shifted to FCV when it becomes available (see section 6 . 1.3). Interestingly, the Base All Max scenario begins to be more successful than the Mid All Max scenario towards the end of this time frame.

In the period 2030-2050, greater differences due to fleet emission targets are more visible than in the initial 2015-2030 period. Perhaps most strikingly, the scenario with no targets and all variables at maximum have an increased market share of BEV compared to the same scenario with targets in place. This remains the most successful scenario (in terms of BEV sales share). This finding alone would suggest that when conditions are favourable towards BEV, fleet emission targets are unimportant. The same observation holds (to a lesser extent) for the marketing and GDP variables. Other anomalies witnessed are that reduced $R \& D$ and Learning effect are more beneficial for BEV than the maximised counterparts or baseline scenarios for the period from 2030 . This is also true to a much more marginal extent from the about 2045 for marketing. These three manufacturer strategies, when maximised, are therefore more supportive of FCV than BEV. Under Mid Targets, there is a rapid sales growth around 2030, which increases even more after 2045 . By 2050, the sales are at around the same amount as the baseline scenario. This again coincides with the introduction of FCV, suggesting that BEV benefits under conditions or strategies that are otherwise unfavourable towards e-mobility as they affect FCV more.

\subsubsection{PHEV sales share}

Up to 2030, PHEV exhibits similar, though more successful, market penetration to BEV. This can be be seen by comparing Fig. 4, which depicts PHEV sales shares,

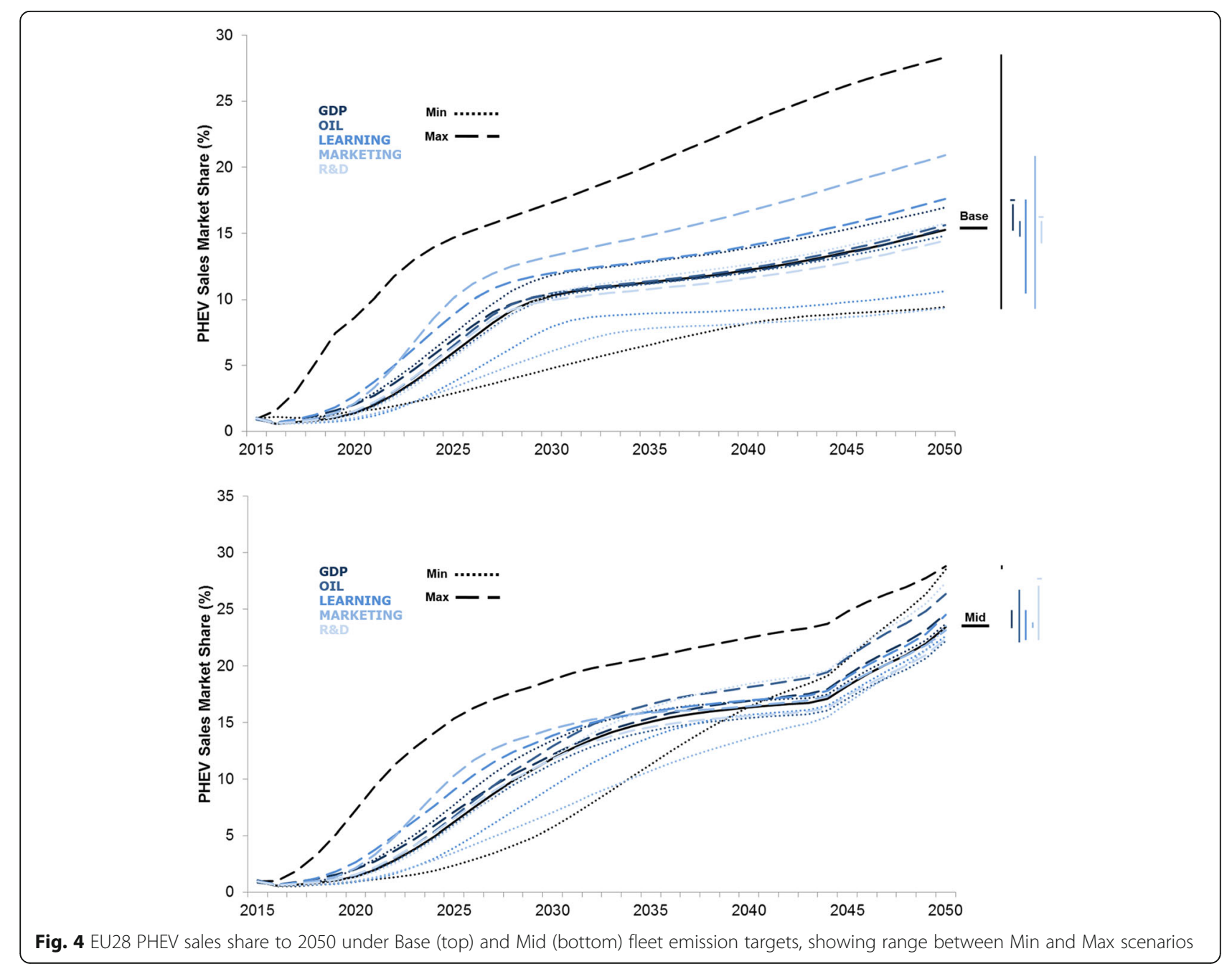


with Fig. 3. One reason for this is that there are two distinct PHEV models available (Petrol and Diesel) whereas only one exists for BEV. However, there are some key differences. The marketing variable does not have as large as an impact on PHEV early in the scenario as it does on $\mathrm{BEV}$, though is the most influential variable by 2030 under either Base or Mid targets. The scenario where the GDP has the lowest growth rate leads to higher sales share than its maximised counterpart or the baseline scenario. This may indicate that under lower economic growth, users are less able to purchase the more expensive BEV. In the early days of an EV market, the PHEV, which is generally the most accessible EV for many users (with its lower price, closer characteristics to conventional vehicles and less reliance on charging infrastructure), may actually relatively benefit from our assumed e-mobility unfavourable conditions.

Up to 2050, there are greater differences between Base and Mid Targets for PHEV than for BEV, suggesting PHEV success is more sensitive to targets being in place than BEV. However, leading from the observations up to
2030 and similar to BEV, the All Minimised scenario continues to lead to a high sales rate and by 2050 is as successful as the All Max scenario. Thus, conditions and strategies that are unfavourable towards e-mobility push sales towards PHEV.

\subsubsection{FCV sales share}

FCV sales shares are shown in Fig. 5. By 2030, the highest FCV market share achieved under any scenario but the All Max is less than 3\%, and the baseline scenario under Mid targets does not reach 1.5\%. Under Base targets only the Maximised R\&D scenario has achieved more than a $1 \%$ sales share. This is because these variables are more beneficial for PiEV during this period. $R \& D$ has the greatest influence on market uptake of FCV. This is in contrast to PiEV and indicates that R\&D funding may go preferentially to FCV. Marketing starts to make a rapid impact towards the end of the time period, as it shifts preferences towards FCV.

Looking at Base conditions between 2030 and 2050, there is what could be considered as a failure to
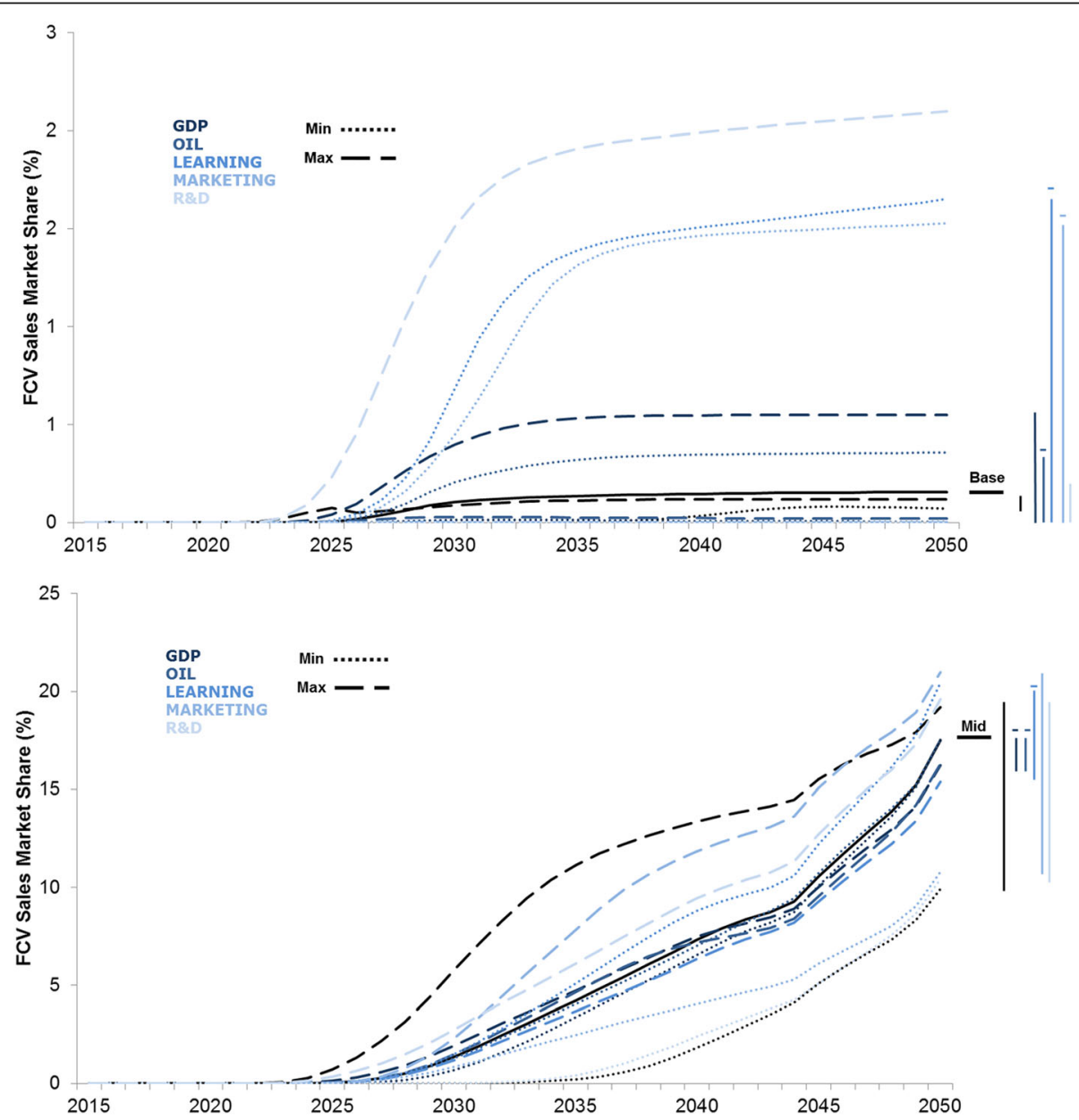

Fig. 5 EU28 FCV sales share to 2050 under Base (top) and Mid (bottom) fleet emission targets, showing range between Min and Max scenarios 
penetrate the market under all scenarios. Indeed from 2030 there is no growth in FCV sales share under any scenario without Mid Targets. Thus we can deduce that, in the confines of this model and our scenarios, manufacturer strategies will not support FCV without longterm, ambitious emission fleet targets in place. There is a very different story regarding mid-term targets however. The baseline scenario has a rather rapid sales growth between 2025 and 2045, which increases further from 2045 when new targets are visible to manufacturer. Marketing and R\&D funding exhibit similar and expected patterns of market penetration though marketing was most influential by the end of the time period. Learning rates scenarios display similar market uptake to the baseline scenario but in the opposite way as expected (lower learning increases share and higher learning decreases share). The 2030 trend continues because this variable supports the earlier maturing PiEV over the lagging FCV technology. Indeed, lower learning rates have led to one of the most successful FCV sales shares by 2050 . Furthermore, lower GDP and Oil price begin to produce greater FCV success around this time. The slowing in sales is due to the fact that from 2035 the current targets are being met, and no new tighter targets are visible to the manufacturer - therefore there is no additional incentivisation for FCV development or marketing that exists under the other variables. These findings suggest that manufacturer strategies are important for FCV success. This supposition is further supported by the large bandwidths between Max and Min scenarios for the manufacturer strategy variables. When all variables are set to their minimum values FCV experiences moderate sales growth from about 2035, leading to a 2050 share of around $10 \%$ of the market. When all variables are set to maximum values however, the market stagnates around 2035 and there is little sales growth until 2045 when there is a push in FCV by the manufacturer in anticipation of the 2050 target. Therefore, even with targets in place, certain market conditions and manufacturing strategies are needed to support FCV development.

\subsection{Testing for the absence of FCVs}

Although it is not realistic to exclude BEV or PHEV from our simulations, because they are already on the road, as we have identified certain interactions between powertrains it seemed an interesting venture to run some selected simulations without FCV. The impact of excluding FCV on EV market shares under various conditions is presented in Fig. 6. This meant for BEV and PHEV marginally higher sales under Base with maximum conditions. However less than $0.5 \%$ of share was added to either BEV or PHEV, as this "extra" share was split between all available powertrains. Under Mid targets both PiEVs attained higher shares (up to around 10\%) under every scenario from just after 2025, when FCV would have made an appearance. However, more interesting than that is to look at the overall EV shares when FCV is excluded. Here we see that without FCV, under baseline scenario and maximum strategies total EV sales are the same. As the PiEVs do not have to compete against FCV for marketing, $R \& D$ funds or learning, they mature more quickly. Also, as they do not directly compete with FCV for sales, growth is more rapid.

\subsection{Testing for subsidy regimes}

Introducing the subsidies of Table 3 (in addition to those of the S1 baseline scenario), as in Fig. 7, has mixed impacts on total EV share under the varying conditions. Under base emission targets and variables, the purchase subsidies S2-3 marginally improve sales. When infrastructure subsidies are introduced (S4) in addition to purchase subsidies, this actually results in lower sales than purchase subsidies alone. This is because the infrastructure subsidies benefit BEV more than PHEV, so more BEV sales are occurring, thus reducing the

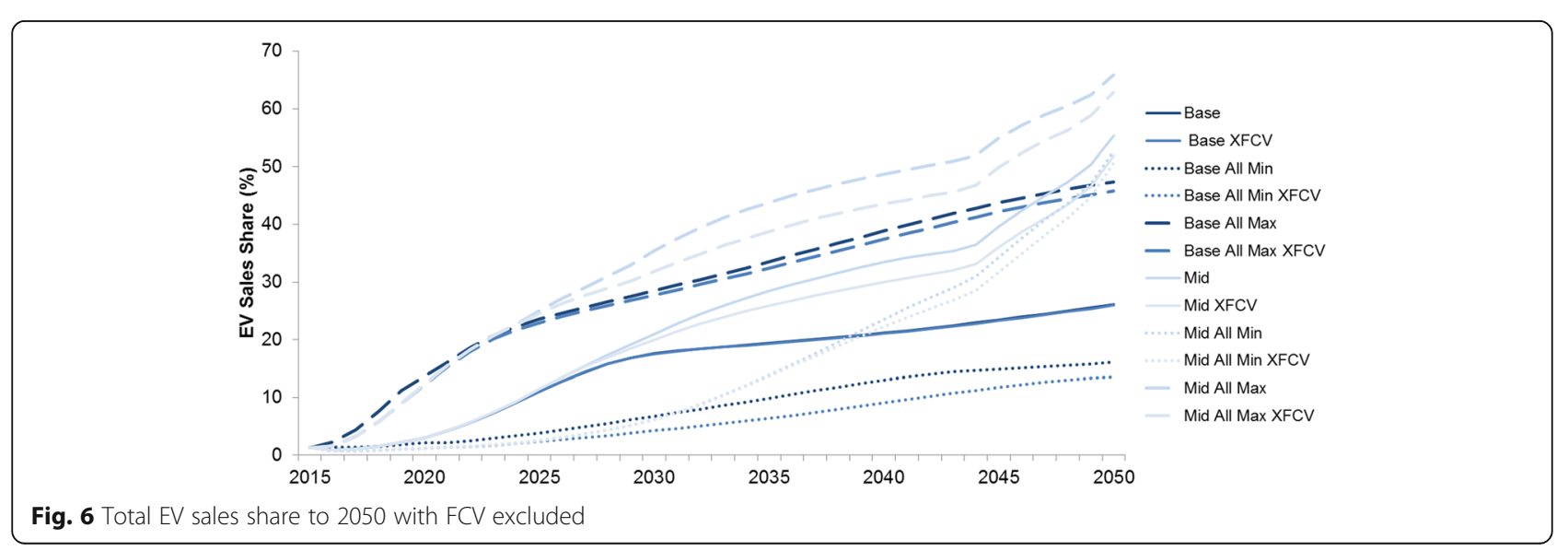




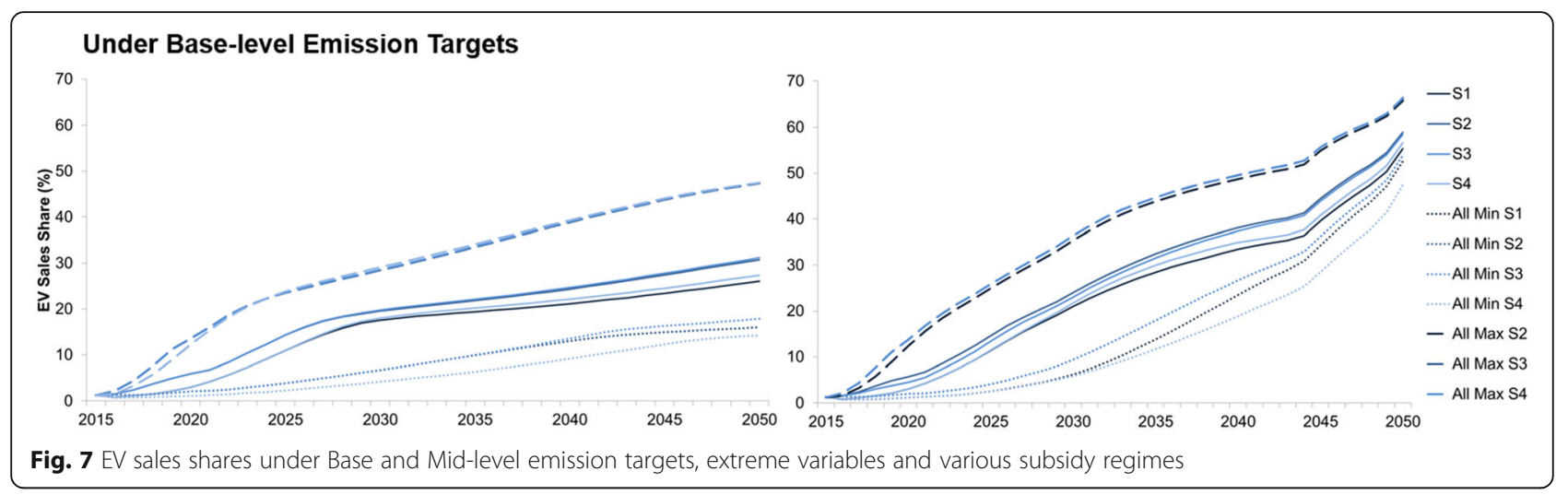

development of PHEV and therefore the overall EV sales. When all variables are at their reduced value, the impact of infrastructure subsidies can be seen as it further reduces sales share from baseline. Purchase subsidies can marginally increase sales, but only after 2040. Finally, when the values of the variables are doubled, although the strongest subsidy scenarios results in the strongest EV sales, it is noted that the actual increase in sales from subsidies in any scenario is only marginal and may not be cost effective. Under Mid-Targets, subsidies make even less impact than under base conditions. This can be seen in Fig. 8.

The EV trends discussed above generally reflect the market pentration of BEV and PHEV. As discussed in previous sections, the FCV market fails under the Base emission targets. With purchase subsidies in place, sales can be encouraged between 2025 and 2035, but then the market stagnates. Infrastructure subsidies alone (S4) can lead to the best sales outlook, with a rapid increase from 2035. However, this still only leads to a $1 \%$ sales share by 2050 . Nonetheless this shows the importance of infrastructure support for FCV under poor conditions. Under Mid emission targets, FCV is less sensitive to subsidies. Purchase subsidies barely increase sales, even when the values of the variables are doubled, and infrastructure subsidies lead to less sales. This is likely due to the subsidies being more beneficial for the PiEVs.

\section{Limitations}

Before concluding on our results, which have been extensively discussed in the previous section, it is worth emphasising the limitations of this research. There have been restrictions to what we could consider and implement due to the structure of the model employed. As such, our recommendations are a base for further study rather than a list of definitive actions. The main limitation of this study is the representation of the manufacturer agent as a conglomerate without competing manufacturers. This prevents us from analysing lock-in effects once a certain manufacturer has decided to invest heavily in a given technology. Thies et al. [21] considered this for two manufacturers. Further work could revolve around explicitly modelling competition among more than two manufacturers. Secondly, we have not considered in detail the wider impact on air pollution and GHG emissions that the introduction of new electric powertrain technologies may have should they become widespread. This may dependen on many factors, mainly upstream emissions, resource sources, power grid implications and the opportunity for energy storage from batteries. Nor have we explicitly considered any other externalities of sustainability concerns of EVs (e.g. resource depletion,

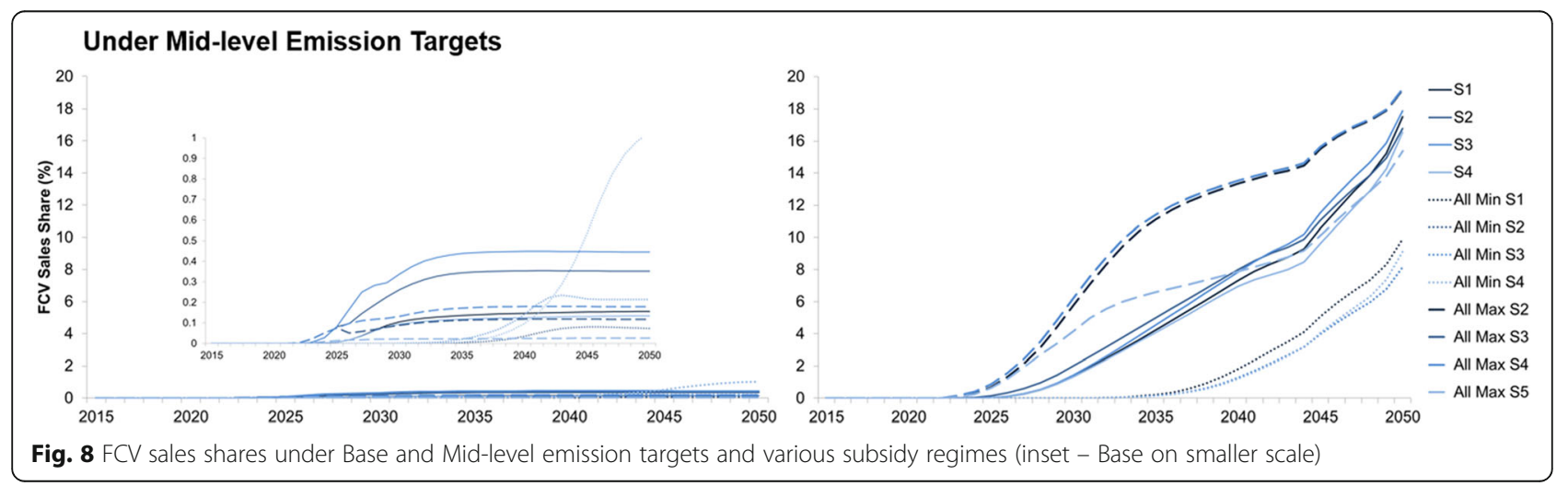


transport poverties, social exclusion). A further restriction is the conservative approach to user choice modelling that is currently employed in the PTTMAM. We recognise the sophistication of the automobile market and purchase preferences and this has already been identified as an area of ongoing improvement and will be addressed in future work. Similarly, our model pre-dates the changing attitude towards diesel fuel due to its high $\mathrm{NO}_{\mathrm{x}}$ emissions and observed related accelerated shift towards EVs. Such changing preferences will be incorporated into future model developments. Finally, we appreciate that with such a long-term time horizon to 2050, that there exists many other uncertainties both in the political-economic future of the EU and within the structure of the transport system, through the introduction of new technologies (e.g. autonomous, smart and connected vehicles) and a possible move towards a sharing economy and mobility-as-a-service (MAAS). However, all research has its boundaries and these limitations do not invalidate our findings, merely contextualise them.

\section{Discussion and conclusion}

The motivation of this research was to gain further understanding on factors which could support or suppress the introduction of electric powertrains, in order to suggest positive strategies that could be considered by automobile manufacturers. The scenarios chosen in this research represented a variety of factors that could influence manufacturer strategies for electrifying their fleet. Fleet emission regulations and vehicle purchase subsidies are already in place across Europe, so formed the basis of a policy background to the results. Two indicators of economic conditions, growth in GDP and oil price, were employed to present the influences within a possible range should the base trajectory not be realised. Strategies are thus characterised by the strength of the learning rate (representing the devotion of nonmonetary resources a manufacturer commits to improving a powertrain, assumed to be proportional to their commitment to the transition), the amount of $R \& D$ funds allocated to improving a powertrain, and the strength of marketing effort put into promoting powertrains. The impacts of the manufacturer strategies and market conditions on EV market shares were presented and discussed. The key observations with regards to industry strategies are:

- Under maximised manufacturer strategy variables and the most favourable economic market condition scenarios, FCV benefits the most of the of the powertrains considered;

- Manufacturer strategies are more crucial for FCV than for PiEV success;
- Strong marketing when both BEV and FCV are introduced is important for the success of both powertrains;

- A lower learning rate benefits BEV, as high learning rates benefit the competing FCV.

These observations are complemented by a series of findings related to the wider policy and economic conditions:

- FCVs may not experience market success in the absence of fleet emission regulations or if PiEVs gain early success (for which economic conditions have a notable influence);

- Differing subsidy regimes, for both purchase and infrastructure, resulted in marginal change in overall EV share, but impact individual EV shares;

- PHEV is the least affected powertrain by either of the offered subsidies.

In terms of policy recommendations, the following can be offered:

- Manufacturers must pay close attention to GDP and oil price conditions despite any of the three strategies examined;

- Greater policy focus is required on the market interaction between PiEVs and FCVs rather than only the competition between EVs and conventional vehicles;

- Fleet emission targets are less important when GDP and oil price conditions are otherwise favourable towards e-mobility;

- Long-term purchase subsidies are important when economic conditions and manufacturer strategies are unfavourable towards e-mobility;

- If the policy goal is to promote FCVs, subsidising the deployment of hydrogen infrastructure has a greater leverage than purchase subsidies.

In conclusion, although technology-neutral policies may be desirable as they do not allow the "cherry-picking" of available technologies, they may inadvertently lead to the suppression of the less mature technologies. Strong marketing is highly influential on uptake at the initial introduction of a new technology, and as this initial uptake determines later success it should be carefully planned for each technology. Manufacturer commitments to new technologies, both monetary and non-monetary, have different influences on the development and maturity of powertrains and so merit further investigation, alongside adoption of future focused strategies that may capitalise on changing attitudes towards mobility, technology and environmental impacts. 


\section{Appendix}

Table 5 Scenarios used in this research

\begin{tabular}{|c|c|c|c|c|c|c|c|c|}
\hline \multirow[t]{2}{*}{ Scenario } & \multicolumn{2}{|l|}{ Policy \& Regulation } & \multicolumn{2}{|c|}{ Economic Conditions } & \multicolumn{3}{|c|}{ Manufacturer Strategies } & \multirow{2}{*}{$\begin{array}{l}\text { Excluded } \\
\text { Powertrains }\end{array}$} \\
\hline & Emission Regulation & Subsidies & GDP ratio & Oil Price & Learning Rate (LR) & Marketing effort & R\&D Share & \\
\hline Base & Base & Base (S1) & Base & Base & Base & Base & Base & None \\
\hline Base S2 & Base & S2 & Base & Base & Base & Base & Base & None \\
\hline Base S3 & Base & S3 & Base & Base & Base & Base & Base & None \\
\hline Base 54 & Base & S4 & Base & Base & Base & Base & Base & None \\
\hline Base XFCV & Base & Base (S1) & Base & Base & Base & Base & Base & FCV \\
\hline Base All Min & Base & Base (S1) & Min & Min & Min & Min & Min & None \\
\hline Base All Min S2 & Base & S2 & Min & Min & Min & Min & Min & None \\
\hline Base All Min S3 & Base & S3 & Min & Min & Min & Min & Min & None \\
\hline Base All Min S4 & Base & \$4 & Min & Min & Min & Min & Min & None \\
\hline Base All Min XFCV & Base & Base (S1) & Min & Min & Min & Min & Min & FCV \\
\hline Base All Max & Base & Base (S1) & Max & Max & Max & Max & Max & None \\
\hline Base All Max S2 & Base & S2 & Max & Max & Max & Max & Max & None \\
\hline Base All Max S3 & Base & S3 & Max & Max & Max & Max & Max & None \\
\hline Base All Max S4 & Base & S4 & Max & Max & Max & Max & Max & None \\
\hline Base All Max XFCV & Base & Base (S1) & Max & Max & Max & Max & Max & FCV \\
\hline Base GDP Min & Base & Base (S1) & Min & Base & Base & Base & Base & None \\
\hline Base GDP Max & Base & Base (S1) & Max & Base & Base & Base & Base & None \\
\hline Base OIL Min & Base & Base (S1) & Base & Min & Base & Base & Base & None \\
\hline Base OIL Max & Base & Base (S1) & Base & Max & Base & Base & Base & None \\
\hline Base LR Min & Base & Base (S1) & Base & Base & Min & Base & Base & None \\
\hline Base PiEV LR Min & Base & Base (S1) & Base & Base & PiEV Min, FCV Base & Base & Base & None \\
\hline Base FCV LR Min & Base & Base (S1) & Base & Base & PiEV Base, FCV Min & Base & Base & None \\
\hline Base LR Max & Base & Base (S1) & Base & Base & Max & Base & Base & None \\
\hline Base LR PiEV Max & Base & Base (S1) & Base & Base & PiEV Max, FCV Base & Base & Base & None \\
\hline Base LR FCV Max & Base & Base (S1) & Base & Base & PiEV Base, FCV Max & Base & Base & None \\
\hline Base MARK Min & Base & Base (S1) & Base & Base & Base & Min & Base & None \\
\hline Base MARK Max & Base & Base (S1) & Base & Base & Base & Max & Base & None \\
\hline Base R\&D Min & Base & Base (S1) & Base & Base & Base & Base & Min & None \\
\hline Base R\&D Max & Base & Base (S1) & Base & Base & Base & Base & Max & None \\
\hline Mid & Mid & Base (S1) & Base & Base & Base & Base & Base & None \\
\hline Mid S2 & Mid & S2 & Base & Base & Base & Base & Base & None \\
\hline Mid S3 & Mid & S3 & Base & Base & Base & Base & Base & None \\
\hline Mid S4 & Mid & S4 & Base & Base & Base & Base & Base & None \\
\hline Mid XFCV & Mid & Base (S1) & Base & Base & Base & Base & Base & FCV \\
\hline Mid All Min & Mid & Base (S1) & Min & Min & Min & Min & Min & None \\
\hline Mid All Min S2 & Mid & S2 & Min & Min & Min & Min & Min & None \\
\hline Mid All Min S3 & Mid & S3 & Min & Min & Min & Min & Min & None \\
\hline Mid All Min S4 & Mid & \$4 & Min & Min & Min & Min & Min & None \\
\hline Mid All Min XFCV & Mid & Base (S1) & Min & Min & Min & Min & Min & FCV \\
\hline Mid All Max & Mid & Base (S1) & Max & Max & Max & Max & Max & None \\
\hline Mid All Max S2 & Mid & S2 & Max & Max & Max & Max & $\operatorname{Max}$ & None \\
\hline Mid All Max S3 & Mid & S3 & Max & Max & Max & Max & Max & None \\
\hline
\end{tabular}


Table 5 Scenarios used in this research (Continued)

\begin{tabular}{|c|c|c|c|c|c|c|c|c|}
\hline \multirow[t]{2}{*}{ Scenario } & \multicolumn{2}{|l|}{ Policy \& Regulation } & \multicolumn{2}{|c|}{ Economic Conditions } & \multicolumn{3}{|c|}{ Manufacturer Strategies } & \multirow{2}{*}{$\begin{array}{l}\text { Excluded } \\
\text { Powertrain }\end{array}$} \\
\hline & Emission Regulation & Subsidies & GDP ratio & Oil Price & Learning Rate (LR) & Marketing effort & R\&D Share & \\
\hline Mid All Max S4 & Mid & S4 & Max & Max & Max & Max & Max & None \\
\hline Mid All Max XFCV & Mid & Base (S1) & Max & Max & Max & Max & Max & FCV \\
\hline Mid GDP Min & Mid & Base (S1) & Min & Base & Base & Base & Base & None \\
\hline Mid GDP Max & Mid & Base (S1) & Max & Base & Base & Base & Base & None \\
\hline Mid OIL Min & Mid & Base (S1) & Base & Min & Base & Base & Base & None \\
\hline Mid OIL Max & Mid & Base (S1) & Base & Max & Base & Base & Base & None \\
\hline Mid LR Min & Mid & Base (S1) & Base & Base & Min & Base & Base & None \\
\hline Mid LR PiEV Min & Mid & Base (S1) & Base & Base & PiEV Min, FCV Base & Base & Base & None \\
\hline Mid LR FCV Min & Mid & Base (S1) & Base & Base & PiEV Base, FCV Min & Base & Base & None \\
\hline Mid LR Max & Mid & Base (S1) & Base & Base & Max & Base & Base & None \\
\hline Mid LR PiEV Max & Mid & Base (S1) & Base & Base & PiEV Max, FCV Base & Base & Base & None \\
\hline Mid LR FCV Max & Mid & Base (S1) & Base & Base & PiEV Base, FCV Max & Base & Base & None \\
\hline Mid MARK Min & Mid & Base (S1) & Base & Base & Base & Min & Base & None \\
\hline Mid MARK Max & Mid & Base (S1) & Base & Base & Base & Max & Base & None \\
\hline Mid R\&D Min & Mid & Base (S1) & Base & Base & Base & Base & Min & None \\
\hline Mid R\&D Max & Mid & Base (S1) & Base & Base & Base & Base & Max & None \\
\hline
\end{tabular}

\section{Authors' contributions}

$\mathrm{GH}$ developed and analysed the scenarios in conjunction with CT. JGV provided additional comments and insights on both literature review and discussions. All authors read and approved the manuscript.

\section{Competing interests}

The views expressed are purely those of the authors and may not in any circumstances be regarded as stating an official position of the European Commission. Otherwise, the authors declare that they have no competing interests.

\section{Publisher's Note}

Springer Nature remains neutral with regard to jurisdictional claims in published maps and institutional affiliations.

Received: 2 October 2017 Accepted: 2 May 2018

Published online: 22 May 2018

\section{References}

1. EC (2016) Communication: a European strategy for low-emission mobility. COM(2016)501final. European Commission. Available from: https://ec.europa. eu/transparency/regdoc/rep/1/2016/EN/1-2016-501-EN-F1-1.PDF.

2. EU (2011) White paper 2011: roadmap to a single European transport area towards a competitive and resource efficient transport system. Luxembourg: European Commission

3. Moro A, Lonza L (2017) Electricity carbon intensity in European member states: impacts on GHG emissions of electric vehicles. Transp Res Part D Transp Environ. https://doi.org/10.1016/j.trd.2017.07.012

4. UCS (2015) Cleaner cars from cradle to grave: how electric cars beat gasoline cars on lifetime global warming emissions. Union of Concerned Scientists: https://www.ucsusa.org/clean-vehicles/electric-vehicles/life-cycle-ev-emissions\#. WVK7rqrRXIU.

5. Thiel C, Krause J, Dilara P (2015) Electric vehicles in the EU from 2010-2014 - is full scale commercialisation near? Luxembourg, European Commission

6. ACEA (2015) ACEA Tax Guide 2015. Brussels, European Association of Automobile Manufacturers

7. EU (2014) Regulation (EU) No. 333/2014 of the European Parliament and of the Council: Amending Regulation (EC) No. 443/2009 to define the modalities for reaching the 2020 target to reduce $\mathrm{CO} 2$ emissions from new passenger cars. Strasbourg: European Commission.

8. EU (2014) Regulation (EU) no 253/2014 of the European Parliament and of the council amending regulation (EU) no 510/2011 to define the modalities for reaching the 2020 target to reduce $\mathrm{CO} 2$ emissions from new light commercial vehicles. Strasbourg: European Commission.

9. Langbroek JHM, Franklin JP, Susilo YO (2016) The effect of policy incentives on electric vehicle adoption. Energy Policy. 94:94-103. https://doi.org/10. 1016/j.enpol.2016.03.050.

10. Lee Y, Kim C, Shin J (2016) A hybrid electric vehicle market pentration model to identify the best policy mix: a consumer ownership cycle approach. Appl Energy 184:438-449.

11. Mersky AC, Sprei F, Samaras C, Qian Zl (2016) Effectiveness of incentives on electric vehicle adoption in Norway. Trans Res Part D 46:56-68

12. Bühne J-A, Gruschwitz D, Holscher J, Klotzke M, Kugler U, Schiemczek C (2015) How to promote electromobility for European car drivers? Obstacles to overcome for a broad market penetration. Eur Transp Res Rev 7(3):1-9. https://doi.org/10.1007/s12544-015-0178-0

13. Button KJ, Pearman AD, Fowkes AS (1982) Car Ownership Modelling and Forecasting. Brookfield, Gower

14. de Wolff $P$ (1938) The demand for passenger cars in the United States. Econometrica 6:113-129. https://doi.org/10.2307/1907143

15. Beggs S, Cardell S, Hausman J (1981) Assessing the potential demand for electric cars. J Econ 16(1):1-19. https://doi.org/10.1016/03044076(81)90056-7

16. Lave CA, K Train 1979 A disaggregate model of auto-type choice. Trans Res Part A 13 (1): p. 1-9. https://doi.org/10.1016/0191-2607(79)90081-5

17. Brownstone D, Bunch DS, Golob TF, Ren W (1996) A transactions choice model for forecasting demand for alternative-fuel vehicles. Res Transp Econ 4:87-129. https://doi.org/10.1016/S0739-8859(96)80007-2

18. Thiel C, Nijs W, Simoes S, Schmidt J, van Zyl A, Schmid E (2016) The impact of the EU car $\mathrm{CO} 2$ regulation on the energy system and the role of electro-mobility to achieve transport decarbonisation. Energy Policy 96:153-166

19. Guzman LA, Orjuela JP (2016) Linking a transport dynamic model with an emissions model to aid air pollution evaluations of transport policies in Latin America. Transportmetrica 5(3):265-280, https://doi.org/10.1080/ 21680566.2016.1169954 
20. Kieckhäfer K, Volling T, Spengler TS (2014) A hybrid simulation approach for estimating the market share evolution of electric vehicles. Transp Sci 48: 651-670. https://doi.org/10.1287/trsc.2014.0526

21. Thies C, Kieckhäfer K, Spengler TS (2016) Market introduction strategies for alternative powertrains in long-range passenger cars under competition. Trans Res Part D Trans Environ 45(Special Issue on Climate Change and Transport):4-27. https://doi.org/10.1016/j.trd.2015.05.002

22. Walther G, Wansart J, Kieckhafer K, Schneider E, Spengler, TS (2010) Impact assessment in the automotive industry - mandatory market introduction of alternative powertrain technologies. Syst Dyn Rev 26(3): 239-261. https://doi.org/10.1002/sdr.453

23. Kieckhäfer K (2013) Marktsimulation zur strategischen Planung von Produktportfolios: Dargestellt am Beispiel innovativer Antriebe in der Automobilindustrie. Springer-Gabler, Wiesbaden: Springer-Verlag.

24. Wansart J (2012) Analyse von Strategien der Automobilindustrie zur Reduktion von CO2-Flottenemissionen und zur Markteinführung alternativer Antriebe: Ein systemdynamischer Ansatz am Beispiel der kalifornischen Gesetzgebung. Springer-Gabler, Wiesbaden: Springer-Verlag.

25. Weikl R (2010) Simulationen zur Abschätzung der Marktanteilsentwicklung unterschiedlicher Antriebsvarianten am deutschen Fahrzeugmarkt: Ein systemdynamisches Modell zur Entscheidungsunterstützung in der strategischen Marktanalyse. GUC Gesellschaft f. Unternehmensrechnung u. Controlling, Chemnitz

26. Meyer G (2009) Analyse und technisch-ökonomische Bewertung von Gesetzesfolgen im Individualverkehr: dargestellt am Beispiel der Automobilindustrie Japans und Deutschlands. Braunschweig: UB Braunschweig.

27. Sterman JD (2000) Business dynamics: systems thinking and modelling for a complex world. McGraw-Hill Higher Education, Boston

28. Abbas KA, Bell MGH (1994) System dynamics applicability to trtansportation modelling. Trans Res Part A 28(5):373-390

29. Shepherd SP (2014) A review of system dynamics models applied in transportation. Transportmetrica B 2(2):83-105. https://doi.org/10.1080/ 21680566.2014.916236

30. Harrison G, Thiel C (2017) An exploratory policy analysis of electric vehicle sales competition and sensitivity to infrastructure in Europe. Tech Forecasting Soc Chang 114:165-178. https://doi.org/10.1016/j.techfore.2016.08.007

31. Pasaoglu G, Harrison G, Jones L, Hill A, Beuadet A, Thiel C (2016) A systems dynamics based market agent model simulating future powertrain technology transition: Scenarios in the EU light duty vehicle road transport sector. Tech Forecasting Soc Chang 104:133-146. https://doi.org/10.1016/j. Techfore.2015.11.028

32. Harrison G, Thiel C (2017) Policy insights and modelling challenges: The case of passenger car powertrain technology transition in the European Union. Eur Trans Res Rev 9(3):37. https://doi.org/10.1007/s12544-017-0252-x

33. Harrison G, Thiel C, Jones L (2016) Powertrain Technology Transition Market Agent Model (PTT-MAM): An Introduction, in JRC Technical Report. European Commission, Luxembourg. https://doi.org/10.2790/719385

34. EC (2016) Commission Staff Working Document. Accompanying the document Communication: A European Stragety for Low-Emission Mobility SWD (2016) 244 final. Available from: https://ec.europa.eu/transport/themes/strategies/news/201607-20-decarbonisation_en. European Commission.

35. Eurostat (2014) Table road_eqr_carm: New registrations of passenger cars by type of motor energy and engine size. http://ec.europa.eu/eurostat/en/ web/products-datasets/-/ROAD_EQS_CARMOT. (Accessed 18/03/14).

36. EC (2013) EU Energy, Transport and GHG Emissions.Trends to 2050. Reference scenario 2013. Luxembourg: European Commission.

37. Eurostat (2014) Table nama_GDP_c - GDP and main components - Current Prices: http://ec.europa.eu/eurostat/web/national-accounts/data/main-tables. (Accessed 29/04/14).

38. Eurostat (2014) Table demopjan - Population on 1 January by age and sex: http://ec.europa.eu/eurostat/en/web/products-datasets/-/DEMO_PJAN. (Accessed 28/04/14).

39. Struben J, Sterman JD (2008) Transition challenges for alternative fuel vehicle and transportation systems. Environ Plann B Plann Des 35(6):1070-1097. https:/doi.org/10.1068/b33022t

40. EMISIA. TRACCS Project. (2013); Available from: http://traccs.emisia.com/. (Accessed 28/04/14).
41. JEC (2014) Well to wheels report version 4a. Joint Research Centre-EUCARCONCAWE collaboration.

42. Energy EU (2014) Fuel Prices. Available from: http://www.energy.eu/fuelprices/. (Accessed 16/04/14)

43. McKinsey (2010) A portfolio of powertrains for Europe: a fact-based analysis. The role of battery electric vehicles, Plug-in hybrids and fuel cell electric vehicles. McKinsey and Company. http://www.eesi.org/files/europe_vehicles.pdf

\section{Submit your manuscript to a SpringerOpen ${ }^{\circ}$ journal and benefit from:}

- Convenient online submission

- Rigorous peer review

- Open access: articles freely available online

- High visibility within the field

- Retaining the copyright to your article

Submit your next manuscript at $>$ springeropen.com 